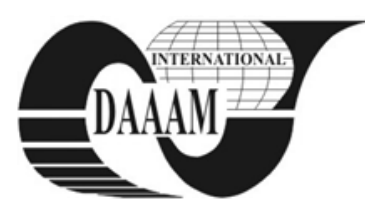

Annals of DAAAM for 2011 \& Proceedings of the 22nd International DAAAM Symposium, Volume 22, No. 1, ISSN 1726-9679 ISBN 978-3-901509-83-4, Editor B. Katalinic, Published by DAAAM International, Vienna, Austria, EU, 2011 Make Harmony between Technology and Nature, and Your Mind will Fly Free as a Bird Annals \& Proceedings of DAAAM International 2011

\title{
A PROPOSAL TO IMPROVE THE ADAPTATION CONTROL SYSTEM IN AUTOMOTIVE SECTOR ENTERPRISES
}

\author{
MAKRAIOVA, J[ana]; CAGANOVA, D[agmar] \& CAMBAL, M[ilos]
}

\begin{abstract}
This article deals with a proposal of alternatives for adaptation control improvement, mainly in its final part, which represents the obtaining the feedback on the process of adaptation and the level of adaptability. It is based on the research, conducted in Peugeot Citroen Automobile Slovakia, Trnava, in 2006. Definition of essential theoretical terms is followed by a brief description of research and proposal of recommendations to improvement of adaptation management
\end{abstract}

Key words: adaptation, orientation, questionnaire, adaptation interview, unskilled production workers

\section{INTRODUCTION}

The phenomenon of globalizations has been persistent since the last decade of 20th century and is still a factor that influences organizations and people these days (Cagáňová et al., 2010). Accelerated changes to the economic system, the effects of integration and the globalization process requires the maximum level of flexibility and adaptability to economic conditions, particularly for employees within corporate organizations. People are no longer willing to passively receive what they are offered, however they wish to experience the feeling of satisfaction and fulfillment at work. For this reason intensive job rotation occurs and business organizations try to ensure quick adaptation to all aspects of a new job position. The corporation contributes to the stability and staff satisfaction from the first working day and thus effectively reduce turnover rate, which often occurs shortly after entering a new job and represent unnecessary financial costs. Effective adaptation management can provide benefits for the company in the form of shortening the initial phase, when the new employee is not performing fully, has not yet mastered all of his working tasks and is not included into the stable working team and wider company. The newcomer feels satisfied in turn, while receiving increased support during the adaptation phase, when experiencing some apprehension and uncertainty about the new environment. Managing the adaptation mechanism with respect to the individuality of each person becomes one of the keys to success for business entities today.

\section{ADAPTATION IN THE WORKING PROCESS}

The basic terms related to the adaptation in working process are ,adaptation“ and „orientation“. These two terms do not have a uniform interpretation of content in the works of Slovak and foreign authors. After careful analysis of several authors' works, it can be concluded, that there is a slight difference between these key terms, which is accurately captured in the following formulations:

Adaptation at work is a process of confrontation and coping with the changed conditions of the individual when taking a new job, or upon transferring to another position within a company.

Orientation when compared with adaptation is a closer term and is defined as consciously managing processes within a company to accelerate, facilitate and guide the employee's adaptation process.

The process of adaptation in the working environment is usually carried out on three basic levels, which divide adaptation into working adaptation, social adaptation and adaptation to the corporate culture. These three types of adaptation can not be understood as a time-separated processes, since they occur more or less parallel with how the new employee is integrated in the company structure. However it is quite common that the ongoing, as well as the final level of adjustment is not equal for all employees. Therefore it is necessary to find ways how to detect this status early and correct identified deficiencies.

\section{CONSEQUENCES FOR A COMPANY NOT CONDUCTING AN ORIENTATION}

It is not too difficult to imagine, how great are the consequences, when the company management does not pay enough attention to the orientation of newcomers. A wide range of negative situations can occur, from slightly to highly unpleasant. But the worst situation is the early termination of employment. If this occurs to a large number of newcomers in one company, this can be regarded as an adaptation crisis. This is a very serious consequence, because the high turnover rate of new employees represents a high cost to the company, because it is subsequently necessary to carry out a new selection process. Therefore, the ultimate goal of adaptation management from the company's perspective is to reduce the newcomer's turnover rate. Influence of sophisticated orientation system on staff turnover rate is shown in figure 1 .

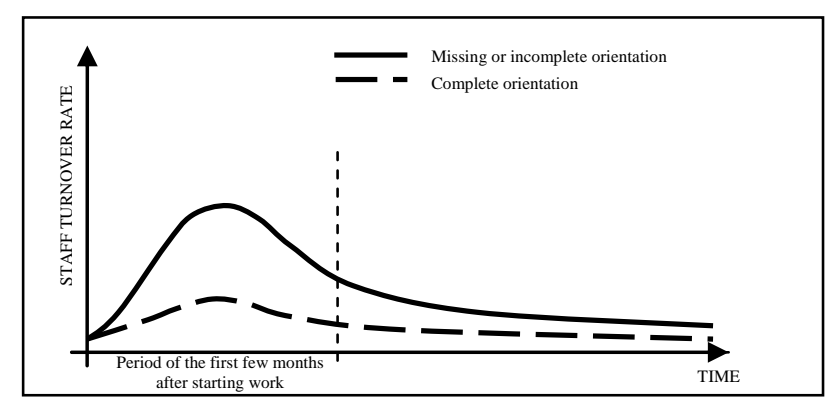

Fig. 1. Influence of orientation system on staff turnover rate (Koubek, 2007)

\section{ESSENTIAL CHARACTERISTIC OF RESEARCH}

An analysis of the current state of adaptation management of new employees was carried out in Peugeot Citroen Automobiles Slovakia in 2006.

Considering the wide range of employee structure and based on three criteria, firstly, the group size, secondly, the importance of the group, and finally expected recruitment volume in the year 
2006 and 2007, a target group of workers was selected, on which analysis and the suggestions were focused. This selected group was the APF group - unskilled production workers.

While carrying out the analysis of the actual state of adaptation control system, the author focused on the individual steps, which are performed as a part of the orientation program in the company. For analysis four basic methods were used, namely: selfobservation, questionnaire survey, the study of internal documents and interviews with newcomers, their supervisors and trainers.

The orientation in PCAS is mainly carried out at the training level, through various training courses, which begin on the first working day. After finishing the training program, they are assigned the status of "operational staff" and they are expected to achieve a high degree of working and social adaptation as well as adaptation to corporate culture. This fact was verified by designing a questionnaire. After statistical evaluation, the questionnaire proved to be a very effective tool to obtain feedback directly from employees and detect the level of their satisfaction and adaptability.

\section{SUGGESTED SOLUTIONS TO IMPROVE THE ADAPTATION CONTROL SYSTEM}

The designed questionnaire offers the opportunity to receive through a formal way the information about the level of adaptability of new staff to the new conditions. All the questions from the questionnaire are listed in the table 1 . It contains 27 statements, which are rated by employees according to the following legend: 1 - the statement is true, 2 - the statement is almost true, 3 - rather disagree with the statement, 4 - the statement is false and two questions which are given statement yes or no.

\begin{tabular}{|c|}
\hline 1. I know the hierarchical structure of my superiors. \\
\hline 2. I know who should I contact in a case of doubt, or when there is a problem. \\
\hline 3. I know my colleagues and I am interested in them. \\
\hline 4. Within the team of my colleagues I feel equal. \\
\hline 5. I feel important and valuable at work. \\
\hline 6. The atmosphere within the team is very friendly and warm. \\
\hline 7. Our supervisor always informs us of all facts that matter. \\
\hline $\begin{array}{l}\text { 8. My supervisor gives me the opportunity to express my views and he is interested in } \\
\text { them. }\end{array}$ \\
\hline 9. My supervisor always appreciates my well-done work. \\
\hline 10. My supervisor takes care for parity with others. \\
\hline 11. My supervisor leads us to mutual respect and tolerance. \\
\hline 12. My supervisor takes the active care of development and progress of our team. \\
\hline 13. I know my competence and responsibility in the workplace. \\
\hline 14. I completely manage all my work tasks. \\
\hline $\begin{array}{l}\text { 15. Training that I attended after starting work in the external trainig centers made me } \\
\text { sufficiently prepared to perform work tasks. }\end{array}$ \\
\hline $\begin{array}{l}\text { 16. I consider the internal training that were conducted in the factory training centers } \\
\text { sufficient to master work tasks. }\end{array}$ \\
\hline 17. I was thoroughly familiar with the principles of safety. \\
\hline $\begin{array}{l}\text { 18. I can orientate myself well in the spatial structure of my workplace and the whole } \\
\text { department. }\end{array}$ \\
\hline $\begin{array}{l}\text { 20. Working conditions such as lighting, noise, dust, temperature and humidity seem } \\
\text { suitable for me. }\end{array}$ \\
\hline $\begin{array}{l}\text { 21. Social equipment (dining room, bar, changing rooms, toilets, etc.) is sufficient for } \\
\text { me. }\end{array}$ \\
\hline 22. Time range and frequency of breaks and lunch break is sufficient for me. \\
\hline $\begin{array}{l}\text { 23. I was informed about all working conditions, social equipment and breaks } \\
\text { management already during the selection process. }\end{array}$ \\
\hline $\begin{array}{l}\text { 24. I know the requirements of the employer for the work rate, which will be required } \\
\text { at the stage of full operation. }\end{array}$ \\
\hline $\begin{array}{l}\text { 25. Have you ever been asked to perform other activities outside of your job } \\
\text { description? }\end{array}$ \\
\hline 26. Have you ever been forced to perform an activity without prior instruction? \\
\hline 27. I was familiar with the values accepted by PCAS. \\
\hline 28. I agree with these values. \\
\hline 29. I have a positive attitude and relationship to the company PCAS. \\
\hline
\end{tabular}

Tab. 1. The list of questionnaire questions

The first 12 statements are focused to evaluate social adjustment, a further 11 statements along with 2 questions to monitor the degree of working adjustment and the last 3 statements are included in the questionnaire to identify the degree of adaptation to the corporate culture. The questionnaire is suitable for new workers, who have already had enough time from their starting day to learn job skills as well as for integration into the social structure and they are expected to achieve a high rate of adaptability. It is a tool of anonymous collection of information, which is suitable for larger groups of workers to reflect accurately the actual situation. The questionnaire is evaluated by arithmetic mean of assigned values for the entire group of participants taking the arithmetic mean determined first on each statement separately and subsequently for each group of statements. Finally, it is necessary to establish dividing values for the categorization of results.

As an alternative method of detecting the degree of staff adaptability by questionnaire, the author suggests conducting a personal interview, called the adaptation interview.

The adaptation interview should consist of the similar questions as used in the questionnaire, also divided into 3 groups of questions focused on adjustment to working conditions, social conditions and corporate culture. The adaptation interview shall take the form of informal structured interview using questions prepared in advance and providing space for employee's free responses and insights. It is more suitable for small groups of workers, or for smaller businesses or departments, because it is much more time-consuming and more expensive. The adaptation interview is performed by a specially trained person who must meet several specific requirements. Although the adaptation interview has an individual form, the results are summarized for the group of employees and are anonymous. The results and conclusions are discussed with the competent persons, to design and adopt corrective steps, that can help actual employees to eliminate dissatisfaction and for future employees this can bring the effects in the form of streamlining the adaptation process. Thereby the adaptation interview becomes a tool for permanent improvement of adaptation control system in the company.

\section{EVALUATION OF THE BENEFITS}

Both suggested solutions after the application in practice and rigorous evaluation, which will not remain unnoticed, will bring several advantages, both for employees and ultimately to the company. The most important in the term of company seem to be the reducing of staff turnover rate and consequently reducing the cost of further selection process and training.

\section{CONCLUSION}

The aim of the research was to propose practical ways, which may contribute to a better adaptation control as well as increasing staff satisfaction. Since the whole concept was tailored for the specific company in specific time, in this work the author tried to select those parts, that can be used anywhere in practice. Usefulness of the proposed solutions is nevertheless very large, because it allows to modify the questionnaire and adaptation interview's questions according to the requirements of a certain company and especially depending on what kind of adaptability is in superiors' focus.

\section{REFERENCES}

Armstrong, M. (1990). A handbook of human resource management, Kogan Page, ISBN: 0749401443, London

Armstrong, M. (1999). Personální management, Grada, ISBN: 8071696145, Prague

Cagáňová, D.; Čambál, M.; Weidlichová Luptáková, S. (2010) Intercultural Management - Trend of Contemporary Globalized World. Electronics and Electrical Engineering, No. 6., (2010) pp. (51 - 54), ISSN 1392-1215

Koubek, J. (2007). Řizení lidských zdrojů, Management Press, ISBN: 8072611683, Prague

Nőlke, J. (2004). Praktický management, Grada, ISBN: 8024709120, Prague 